\title{
Strategi Marketing Mix Perspektif Ekonomi Islam pada Hotel Semesta di Kota Semarang
}

\author{
Farkhi Hazami dan Rosida Dwi Ayuningtyas* \\ Program Studi Ekonomi Islam, Fakultas Ekonomi, Universitas Wahid Hasyim \\ "Email: rosida@unwahas.ac.id
}

\begin{abstract}
This research is a qualitative research to examine the application of Islamic economic perspective marketing in the business of sharia services in Semarang City, a case study in the sharia industry in the Sharia Universe of Semarang City. The focus of this research is to explain how the application of Islamic economic perspective marketing mix to hotel universe sharia. In this study focuses on product, price, promotion, distribution / place carried out by the hotel universe syariah city all the perspectives of Islamic economics theoretically. The purpose of this study is to provide a conclusion about the application of marketing mix namely product, price, promotion, and distribution / place carried out by hotel universe syariah Islamic economic perspective. This study uses a qualitative approach to the case study method. The data analyzed are the results of interviews, documentation and observations with the field of marketing, namely product, price, promotion, and distribution / place in the Semarang Sharia Universe Hotel. The results showed that the application of Islamic economic perspective marketing mix at the Semarang City Semesta Hotel had not been effective. Because in terms of Sharia Universe Hotel products still have not fully implemented several elements and sub elements provided by the Republic of Indonesia's Creative Economy Tourism Minister Regulation Number 2 of 2014 concerning guidelines for sharia hotel business operators.
\end{abstract}

Keywords: Strategy, Marketing mix, Islamic Perspective, Sharia Industry

\section{PENDAHULUAN}

Indonesia sebagai negara berkembang mengalami perubahan dari Negara bercorak agraris menuju industri, fungsi dari industri yaitu mengubah bahan baku kedalam barang jadi, dimana produk tersebut bisa dinikmati oleh konsumen atau masyarakat. Suatu usaha tidak akan mampu bertahan ketika perusahaan itu tidak mampu bersaing dengan usaha-usaha lain. Dalam menghadapi persaingan yang semakin luas, diharuskan perusahaan menerapkan strategi pemasaran yang dapat membuat usaha perusahaan tetap berkembang.

Menurut Nurcholifah, (2014) dalam menyediakan kebutuhan masyarakat, terlebih dahulu pemasar dapat melakukan penelitian (riset) pasar. Sehingga produk yang diciptakan dapat dinikmati dan memberikan manfaat atau kepusan bagi masyarakat. Produk yang di ciptakan perusahaan-pun harus produk yang bermutu serta berkualitas, sehingga masyarakat menemukan kepuasan tersendiri dari produk yang unggul dan juga menjadikan umur panjang bagi perusahaan.

Kegiatan pemasaran ini pada intinya memfokuskan diri pada produk, penerapan harga, kebijakan distribusi dan cara promosi yang dalam hal ini dikenal sebagai bauran pemasaran. Kegiatan pemasaran tentunya membutuhkan suatu strategi. Strategi ini tentu harus mampu memberikan kontribusi terhadap pencapaian tujuan perusahaan yaitu peningkatan mutu dan luasnya jaringan pemasaran. Bauran pemasaran (marketing mix) adalah strategi pemasaran untuk menggunakan dan mengefektifkan produk, periklanan, harga, saluran distribusi, dan unsur-unsur lain. Salah satu cara untuk mengetahui dan mengidentifikasi sebuah keberhasilan dalam pemasaran yaitu dengan bauran pemasaran. Setelah perusahaan memutuskan strategi pemasaran kompetitifnya secara keseluruhan, perusahaan harus mulai menyiapkan perencanaan bauran pemasaran secara rinci. 
Bauran pemasaran adalah seperangkat alat pemasaran yang digunakan perusahaan untuk mencapai tujuan pemasarannya dalam pasar sasaran. Alat pemasaran tersebut dapat dikelompokan menjadi empat kelompok variabel yaitu produk (product), harga (price), distribusi (place), dan promosi (promotion). Keempat variabel tersebut yang akan menentukan tingkat keberhasilan pemasaran dan semua itu ditujukan untuk memberikan kepuasaan pada pangsa pasar atau konsumen yang dipilih. (Murti Sumarni, 2002)

Sula dan Kartajaya (2006) yang dikutip dalam Arham (2010) lebih jauh menekankan bahwa pemasaran islami, selain menjadi spiritual dan etis, juga harus realistis, kreatif dan tidak terlalu kaku dalam mempraktikkan pemasaran Islam, dimana norma-norma keislaman tidak dilanggar. Sedangkan menurut Mohd Ali Bahari, dkk (2017) "Marketing from Islamic perspective was discussed in detail in the previous researches. A thorough review of the literature on marketing was done with the purpose of coming up with the viable strategies to propel and ensure that Islamic products penetrate both the Muslims and non-Muslims markets. The general conclusion was that, Islamic marketing is endowed with various features that ensure that a justice and fairness exist between the buyer and the seller and have high potential of being generally accepted not only by the Muslims but also by the non-Muslims. However, market segmentation must be adopted as one of the key strategy for the penetration of Islamic market beyond Muslims market due to the fact that, it put into consideration diverse geographical location, culture and religion"

Menurut Abul Hassan Chachi, A. \& Abdul Latiff, S. (2008) "Given the key importance of customer trust in the Islamic bankingand financial services sector, it is recommended that Islamic banks should emphasize frontline employees' Islamic ethical behaviours that particularly lead to customer trust. Put simply, they need to be honest and implement low-pressure selling techniques "

Pernyataan diatas dimaksudkan adalah kepercayaan para pelanggan sangat penting bagi berlangsungnya usaha secara islami, sehingga pelaku usaha harus lebih menekankan berberilaku jujur dan beretika secara prinsip islam serta menekankan tehnik penjualan yang jujur dan tidak melakukan kecurangan.

Dewasa ini, dengan banyaknya persaingan industri di negara Indonesia menjadikan perusahaan berpikir keras untuk merangkul masyarakat atau konsumen akan barang atau jasa yang dikeluarkan oleh industri tersebut. Salah satu dampak dari persaingan tersebut adalah munculnya beberapa industri syariah yang berkiblat pada kesesuaian akan hukum Islam terhadap barang / jasa yang dijual dengan metode pemasaran secara syariah.

\section{METODE PENELITIAN}

\section{Jenis Penelitian}

Dalam penelitian ini penulis menggunakan penelitian lapangan (field research), yaitu penyusun akan mengumpulkan data dengan cara mendatangi langsung ke lapangan yang menjadi objek penelitian untuk mempelajari secara intensif tentang berbagai permasalahan yang diteliti.

\section{Sumber Data}

Data merupakan keterangan-keterangan tentang suatu hal, dapat berupa sesuatu hal yang diketahui atau yang dianggap atau anggapan. Atau suatu fakta yang digambarkan lewat angka, simbol, kode, dan lain-lain. (Hasan, 2002) Data penelitian dikumpulkan baik lewat instrumen pengumpulan data, observasi, wawancara maupun lewat data dokumentasi. Adapun yang menjadi sumber data dalam penelitian ini adalah :

1. Pimpinan Perusahaan Hotel Semesta Syariah Kota Semarang

2. Penyedia Jasa Hotel Semesta Syariah Kota Semarang

3. Konsumen Hotel Semesta Syariah Kota Semarang

Dalam menganalisis data, peneliti juga harus menguji keabsahan data agar memperoleh data yang valid. Untuk memperoleh data yang valid, maka dalam penelitian ini digunakan lima teknik pengecekan dari sembilan teknik yang dikemukakan oleh Moleong. "Kelima teknik tersebut adalah: 1) Observasi yang dilakukan secara terus menerus (persistent observation), 2) Trianggulasi (trianggulation) sumber data, metode, dan penelitian lain, 3) Pengecekan anggota (member check), 4) Diskusi teman sejawat (reviewing), dan 5) Pengecekan mengenai ketercukupan referensi (referential adequacy check)", Sugiono (2005) 


\section{HASIL DAN PEMBAHASAN}

Analisis Ekonomi Islam Terhadap Penerapan Strategi Marketing Mix di Industri Syariah Hotel Semesta Syariah Kota Semarang.

Strategi marketing mix merupakan salah satu cara yang digunakan oleh Industri Syariah Hotel Semesta Syariah guna mempertahankan kelangsungan hidup perusahaan dalam persaingan industri yang semakin ketat ini. Pencapaian sebuah keberhasilan dalam perusahaan yang bergerak dalam bidang jasa atau produksi maupun konsumsi tidak dapat dicapai tanpa proses panjang yang melibatkan banyak komponen. Salah satu komponen yang perlu diperhatikan adalah aspek sosial agama yang tidak bisa dilepaskan begitu saja.

1. Strategi Produk

Produk yang dihasilkan oleh Industri Syariah Hotel Semesta Syariah sudah memenuhi kriteria dalam marketing mix atau bauran pemasaran. Bisa dilihat dari segi kualitas, keragaman, ciri khas, dan kualitas pelayanannya. Dengan menerapkan Peraturan Menteri Pariwisata Dan Ekonomi Kreatif Republik Indonesia Nomor 2 Tahun 2014 Tentang Pedoman Penyelenggaraan Usaha Hotel Syariah, Hotel Semesta adalah kategori Hotel Syariah Hilal-2 yaitu :

A. Aspek produk yang terdiri dari 11 unsur dan 40 sub unsur.

B. Aspek pelayanan yang terdiri dari 10 unsur dan 28 sub unsur.

C. Aspek pengelolaan yang terdiri dari 3 unsur dan 6 sub unsur.

i. Aspek produk Hotel Semesta Syariah ada 3 sub unsur yang tidak dijalankan atau belum ada, yaitu :

- Kriteria mutlak Tersedianya peralatan yang praktis di kamar mandi tamu untuk bersuci dengan air di urinoir dan kloset,

- Tersedia peralatan untuk berwudhu yang baik di kamar mandi tamu,

- Tersedianya penyekat antara urinoir satu dengan urinoir yang lain untuk menjaga pandangan

ii. Aspek pelayanan Hotel Semesta Syariah ada 3 unsur yang belum ada antara lain yaitu Olahraga, rekreasi dan kebugaran, Kolam renang dan Spa.

iii. Aspek pengelolaan Hotel Semesta Syariah ada 1 sub unsur yang tidak di jalankan atau belum ada yaitu:

- Belum Memiliki struktur organisasi yang mengakomondasi Dewan Pengawas Syariah.

- Produk dan layanan jasa yang suguhkan Industri Syariah Hotel Semesta Syariah sudah sesuai dengan nilai kehalalan, bermutu, bermanfaat dan juga berhubungan dengan kehidupan manusia. Dan yang paling penting untuk diperhatikan adalah produk yang diperdagangkan halal dan tayyib, tidak merusak akidah, etika dan moral manusia.

2. Strategi Harga

Harga produk yang diterapkan Industri Syariah Hotel Semesta Syariah sudah sesuai dengan pasar yang wajar. Penentuan harga yang dilakukan tidak jauh berbeda dengan penentuan harga pada umumnya, yaitu dengan menjumlahkan seluruh biaya-biaya mulai dari biaya bahan dasar sampai ke biaya operasionalnya. Dari biaya-biaya tersebut dijumlahkan dan nantinya dihitung untuk mencari laba yang maksimal. Dalam mengambil keuntungan juga tidak melampaui kewajaran sehingga tidak ada praktik tadlis ataupun gharar. Tadlis yaitu praktek penipuan, baik penipuan pada komoditas dan alat pembayarannya maupun pada penipuan harga.

Dalam menetapkan dan memasang harga Industri Syariah Hotel Semesta Syariah sudah mengambil margin keuntungan, tanpa memberi tahu pembeli berapa keuntungan yang diambilnya. Sebagaimana Nabi Muhammad SAW bersabda "Janganlah kamu menjual menyaingi penjualan saudaramu".

3. Strategi Promosi

Industri Syariah Hotel Semesta Syariah menerapkan strategi promosi melalui periklanan atau Advertising. Periklanan atau advertising dilakukan sebagai alat komunikasi untuk menyampaikan pesan agar mendapatkan respon dari konsumen dan umpan balik dapat diterima 
sehingga terjadi transaksi yang menguntungkan. Kegiatan periklanan yang dilakukan Industri Syariah Hotel Semesta Syariah bertujuan untuk menginformasikan mengenai keberadaan perusahaan dan produk yang ditawarkan agar lebih mendapat perhatian dari konsumen.

Promosi yang dilakukan oleh Industri Syariah Hotel Semesta Syariah sudah sesuai dengan kriteria dalam strategi marketing mix. Dengan tujuan dapat memperluas jaringan pemasaran dan pengembangan produk dan berinovasi Industri Syariah Hotel Semesta Syariah dalam berpromosi sesuai dengan kenyataan produk yang dijual, tidak melebih-lebihkan dan melakukan sumpah untuk menarik konsumen. Karena kejujuran merupakan kunci utama dalam promosi, kita diperbolehkan melakukan promosi seluas-luasnya asalkan promosi yang dilakukan tidak melebih-lebihkan produk yang kita jual. Artinya implementasi promosi Hotel Semesta Syariah melakukan standar operasional perusahaan bawa dalam promosi mengedepankan jejujuran, etika dalam berkomunikasi dan menghindari unsur yang dilarang oleh Agama islam.

4. Strategi Distribusi/Tempat

Proses distribusi yang dilakukan Industri Syariah Hotel Semesta Syariah sudah sesuai dengan kriteria marketing mix dalam Ekonomi islam. Tidak ada pihak yang dirugikan, baik dari pihak produsen, distributor, dan konsumen. Kemudahan akses dan lokasi yang strategis Hotel Semesta Syariah menjadikan nilai plus bagi perusahaan, Keberadaan Hotel Semesta Syariah yang dekat dengan warga Kelurahan Bangunharjo tersebut juga merekrut tenaga / kariyawan warga sekitar.

\section{KESIMPULAN}

Strategi marketing mix yang diterapkan Industri Syariah Hotel Semesta Syariah yang mencakup produk, penetapan harga, kegiatan promosi, dan saluran distribusi menerapkan nilainilai islam dari beberapa aspek. Dengan demikian dapat dikatakan bahwa strategi marketing mix yang digunakan Industri Syariah Hotel Semesta Syariah memberikan dampak positif bagi perusahaan. Hal tersebut dapat dilihat dari meningkatnya jumlah konsumen dari tahun ke tahun dan perusahaan dapat mempertahankan kelangsungan hidupnya hingga saat ini dan mampu bersaing di pasaran.

1. Dalam Penerapan Pedoman Penyelenggaraan Usaha Hotel Syariah

a. Produk

Produk yang dimaksud dalam penelitian ini adalah apa yang tersedia dan dapat digunakan oleh tamu hotel serta dapat dimanfaatkan secara maksimal. Ada Sembilan unsur dari aspek produk, akan tetapi ada dua aspek dan 3 sub unsur yang belum terpenuhi di Hotel Semesta Syariah Kota Semarang yaitu belum tersedianya fasilitas berupa ruang SPA dan kolam renang dan Tidak tersedianya peralatan yang praktis di kamar mandi tamu untuk bersuci dengan air di urinoir dan kloset, tidak tersedia peralatan untuk berwudhu yang baik di kamar mandi tamu,tersedianya penyekat antara urinoir satu dengan urinoir yang lain untuk menjaga pandangan, hal ini dikarenakan dalam proses masa perkembangan dan melihat dari lokasi.

b. Pelayanan

Pelayanan adalah sebuah proses pemenuhan kebutuhan melalui aktivitas orang lain yang menyangkut segala usaha yang dilakukan orang lain dalam rangka mencapai tujuannya. Dalam aspek pelayanan terdapat enam unsur, akan tetapi ada dua unsur yang belum terpenuhi yaitu olahraga, dan kebugaran serta fasilitas layanan SPA.

c. Pengelolaan

Pengelolaan adalah proses mengkoordinasi dan mengintegrasikan semua sumber daya, baik manusia maupun teknikal, untuk mencapai berbagai tujuan khusus yang ditetapkan dalam suatu organisasi. Di Hotel Semesta Syariah Kota Semarang manajemen usahanya sudah cukup baik, terbukti dengan memiliki dan menerapkan sistem jaminan halal, Terapi dalam Struktur organisasi Hotel Semesta Syariah tidak mencantumkan Dewan Pengawas Syariah. 


\section{DAFTAR PUSTAKA}

Abul Hassan Chachi, A. \& Abdul Latiff, S. (2008). Islamic Marketing Ethics and its Impact on Customer Satisfaction in The Islamic Banking Industry. JKAU: Islamic Economy,

Alserhan, Baker Ahmad, Principles of Islamic Marketing, England : Gower Publishing Limited, 2011.

Andiwarman Karim. 2004. Bank Islam Analisis Fiqih dan Keuanagan. PT Raja Grafindo persada.Jakarta

Anwar A. Pitchay, Marketing Mix from Islamic Marketing Perspective, (Malaysia: IIUM, 2012)

Antonio, Muhammad. 2009 Bank Syariah : dari Teori ke Praktik. Jakarta : Gema Insani Press.

Andiwarman Karim 2006. Bank Islam-Analisis Fiqih dan Keuangan. Jakarta : PT. Raja Grafindo Persada

Al-Qardhawi, Yusuf. 2001. Norma dan Etika Ekonomi Islam. Jakarta: Gema Insani Press.

Buchari Alma, Manajemen Bisni Syariah: Sebuah Kajian Historis dan Kontemporer, Jakarta: Raja Grafindo Persada, 2006.

Djakfar, Muhammad (2008) Etika bisnis Islami: Tataran teoritis dan praktis. UIN-Maliki Press, Malang. ISBN 979-24-3008-3

Hamzah Ya'qub, Kode Etik Dagang menurut Islam, (Bandung: Diponegoro, 1984).

Kartajaya, Hermawan, dan Syakir,M.Sula, Syariah Marketing, Bandung : PT Mizan Pustaka, 2006.

Kaulla, R., (1940) Theory of the Just Price, terjemahan bahasa Inggris oleh Robert D. Hogg (London: George Allen, 1940)

Mahabub Alom dan Shariful Haque, Marketing: An Islamic Perspective, World Journal of Social Sciences Vol. 1. No. 3. Juli 2011.

Muhammad. (2004) Manajemen dan Bank Syariah. Yogyakarta: Ekonisia.

Nurcholifah, 2014 “ Strategi Marketing Mix Dalam Perspektif Syariah”.

Nirwanda. 2015. Ikhtiar Menjadi Produsen Halal Lifetyle, Dalam GATRA.). Niazi, Liaquat Ali Khan. (1996). Islamic Law of Contract (ResearchCell. Dyal Sing Trust Library) Lahore.

Taqiyuddin AN-Nabhani. an-Nizhaamu al-Iqtishadi fi al-Islaam. Diterjemahkan oleh Redaksi AlAzhar Press. Sistem Ekonomi Islam. $\quad$ Bogor: Al-Azhar Press. 2009. Cetakan Pertama.

Wulpiah, 2017 Pemikiran Ibnu Khaldun tentang Mekanisme Pasar. Jurusan Syariah dan Ekonomi Islam STAIN Syaikh Abdurahman Siddik Bangka Belitung.

Sulaiman Wahab, 2013 Marketing Mix Dan Relgi Terhadap Minat Masyarakat. FE Universitas Widyagama Malang

www.bps.go,id_(Jumlah penduduk muslim indonesia) diakses tanggal 11 april 2018.

http://www.kemenpar.go.id/asp/index.asp diakses pada tanggal 20 april 2018

Yusuf as-Sabatin. Al-Buyu' al-Qadimah waal Mu'ashiraah wa al Burshaat al-Mahaaliyyah wa ad-Duwaliyyah, Diterjemahkan oleh Yahya Abdurrahman, Bisnis Islami \& Kritikan Atas Praktik Bisnis Ala Kapitalis. Bogor: Al-Azhar Press. 2009. Cetakan Pertama. 